\title{
Fuzzy with Hysteresis Controller for Power-Quality Improvement of Grid Interconnected System
}

\author{
K. Venkateswarlu, G.V. K Murthy, D. Prasad, K. V Narayana
}

\begin{abstract}
The grid connected distribution systems are providing the energy to the load from the grid. During the period of energy transmission, the issues are occurred on the power quality in transmission line. In the power system, the power quality issues are occurred due to the following issues as instability of the system, voltage sag, harmonic distortion, over voltage, unbalanced voltage etc. In this paper, the power quality improvement is designed using the inverter which compensates the voltage and current when the fault occurred. This inverter is used to inject the power using a DC source. This improvement of power quality is controlled by the hysteresis controller with fuzzy logic control. The feedback is given to the controller which reduces the error from the system and provides the control variables to the inverter terms of switching gate signals.
\end{abstract}

Keywords: Grid, fuzzy logic, hysteresis controller, power quality.

\section{INTRODUCTION}

In distribution side voltage level, the generation of electrical power is achieved by the micro grids, distributed energy sources that integrated in small scale. In between the operation of distribution system and micro sources and it provide can be security, better flexibility and it is achieved by the power electronics connection and the occurrence power quality problems in distribution system due to the presents of unbalanced load as well as non linear loads. The power quality issues also occurred while the loads consumed high reactive power. In day to day life the growth of power devices to control and improve the quality of power is increased. The synchronous static compensator is an interesting power compensation device that realized by the connection of voltage source inverter that in shunt. Its advantages are fast control and flexibility. For the distribution grids with low voltage, the DSTATCOM voltage regulator is used. To control the reactive power supply in micro grids the custom device is used which is called distribution STATCOM (DSTATCOM).

Revised Manuscript Received on February 05, 2020.

* Correspondence Author

K. Venkateswarlu*, Department of EEE, PACE Institute of Technology \& Sciences, Ongole, India. Email: kalluri.venkateswarlu@gmail.com

G.V.K Murthy, Department of EEE, PACE Institute of Technology \& Sciences, Ongole, India. Email:murthy260@gmail.com

D.Prasad, Department of EEE, PACE Institute of Technology \& Sciences, Ongole, India. Email: prasad.march17@gmail.com

K.V Narayana, Department of EEE, PACE Institute of Technology \& Sciences, Ongole, India. Email: narayana.katragadda@gmail.com

(C) The Authors. Published by Blue Eyes Intelligence Engineering and Sciences Publication (BEIESP). This is an open access article under the CC BY-NC-ND license (http://creativecommons.org/licenses/by-nc-nd/4.0/)
The model predictive control algorithm is implemented to analyze the reactive power compensation. In the renewable energy systems such as wind, PV system comprises the generator to produce the power then it is

rectified using pulse width modulation technique for the purpose of DC constant supply to the inverter. The passive filter with fuzzy control is implemented to improve the quality of power. The power consumption is high because of high amount of loads that are in nonlinear and it is caused to system harmonic current. This current causes overloading in capacitor, less efficiency and the changes in the voltage magnitude. An important issue in transmission line considered as voltage sag and it is prevented by the utilization of dynamic voltage regulator. The active power filter and the distributed generator are used in perfect way to mitigate the unbalance voltage as well as voltage harmonics. The desired power compensation is established using the both distribution generator and active filter. The excess power demand requirement is due to the population rising. The non conventional energy sources are used to mitigate such kind of issues. The electrical utility operation and performance are increased using by the non conventional renewable energy sources. The perturbation voltage, harmonics in voltage are presented due to the disturbances that are appeared in the power distribution network. When the fault occurs in grids the level of voltage is dropped below the $80 \%$ of the voltage at point of common coupling. The UPFC device of FACTS is performed to improve the voltage of WECS while the fault is presented.

\section{PROPOSED METHOD}

In this proposed system, the power quality issue of sag voltage is improved during the period of fault occurred or the external faults and this compensation is done by using a voltage source inverter. The power is provided to the inverter by a DC voltage source. The given source energy is converted into AC and then it is injecting to the transformer. The three phase current is injected and compensates the current that below the nominal value. In this paper proposes the fuzzy with HC controller to control the performance of the inverter.

\section{A. Fuzzy logic controller}

The fuzzy controller is used to control the system performance along with the rules defined to do the process based on the designed system. To provides the better system stability, the error from the plant to be minimized. The logic rules defined using the fuzzy sets and member functions. The fuzzy editor in the MATLAB is illustrated in figure. 3.

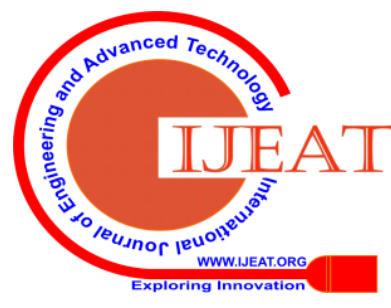


In this control the two inputs are given to the system named as input1 and input2 and have an output.

To give the corresponding values to the variables the member functions are used and the input 1 and input 2 member functions are shown in figure. 4 and figure. 5 are respectively.

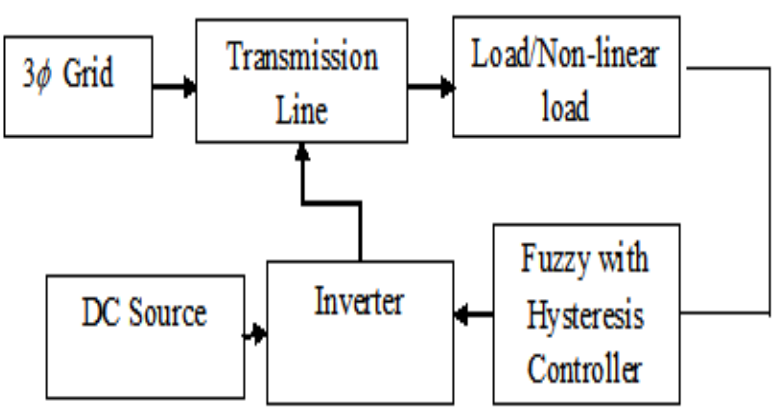

Fig. 1.Block diagram of the proposed system

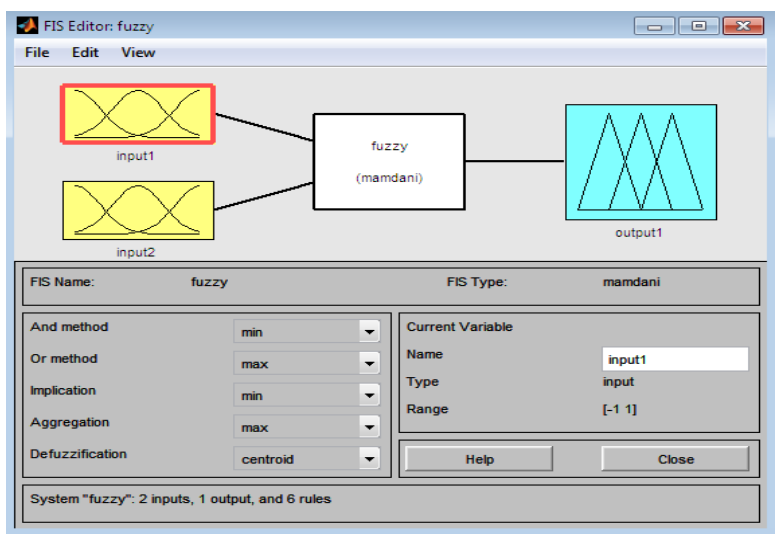

Fig. 2.Fuzzy editors in the MATLAB

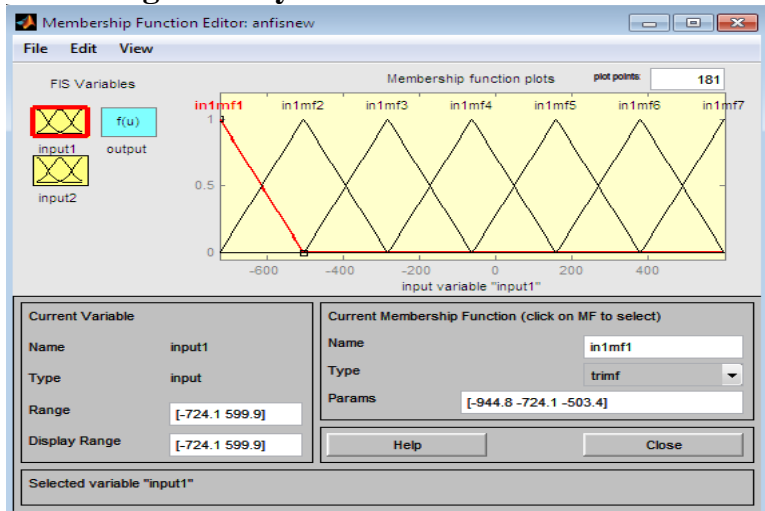

Fig. 3.Member function of input 1

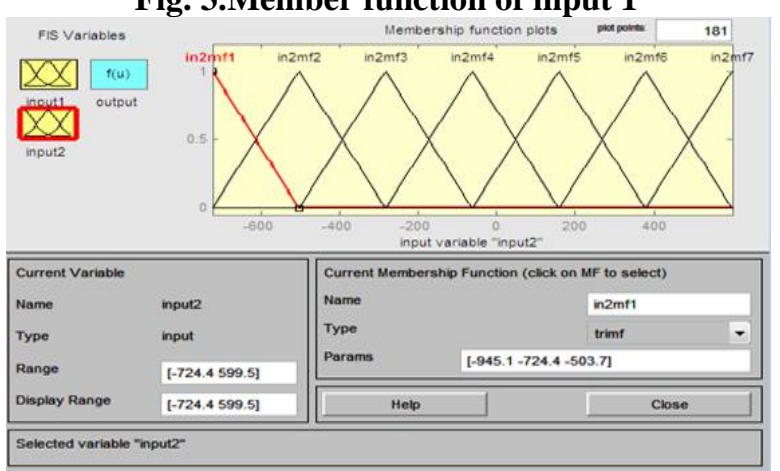

Fig. 4.Member functions of input 2

\section{B. Hysteresis controller}

The hysteresis current controller is used to the current error reduction and provides the switching signals to the power switches of inverter. The controller performs based on the reference as shown in figure. 5 and for the purpose of to ramp the current the power switches are controlled by the up and down of inductance. But it has two limits for the up and down of the current ramping. When the upper limit of the hysteresis controller exceeds, the inverter supplies negative voltage to the inductor and due to this, the inductor current is decreased. When the lower limit of the hysteresis controller is reached, the inverter supplies the positive voltage to the inductor. Thus the inductor current is increased and the cycles are repeated.

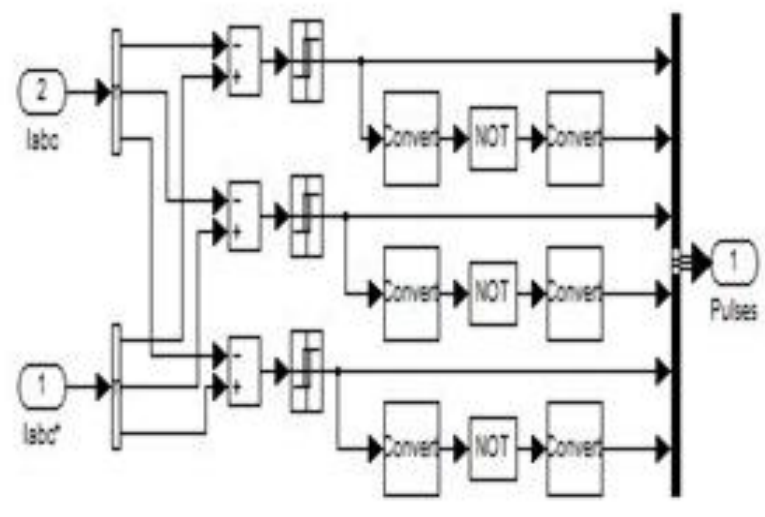

Fig. 5.Hysteresis controllers

Operation of the proposed controller is to compares the reference current and load current of the output load and it generates the error signal (e) to the fuzzy control. The input of the fuzzy is an error signal and the change in error signal $\frac{d(e)}{d t}$ produces the output signal. This is send to the hysteresis controller. An error signal in the HC controller generates pulse to the inverter.

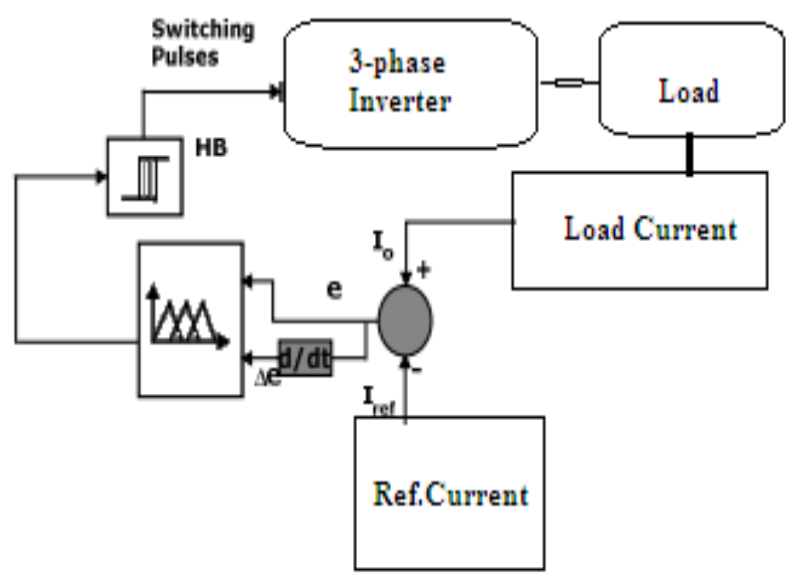

Fig. 6.Fuzzy with HC controller

\section{SIMULATION AND RESULTS}

The current compensation and power quality improvement of distribution system that interfaced with grid is proposed. The Proposed Simulink model is shown in figure. 7.

Published By: 
This implemented system is controlled by using the Fuzzy controller rules with hysteresis current controller and the grid connected system current flow is compensated. This control method leads to power quality improvement of the proposed system.

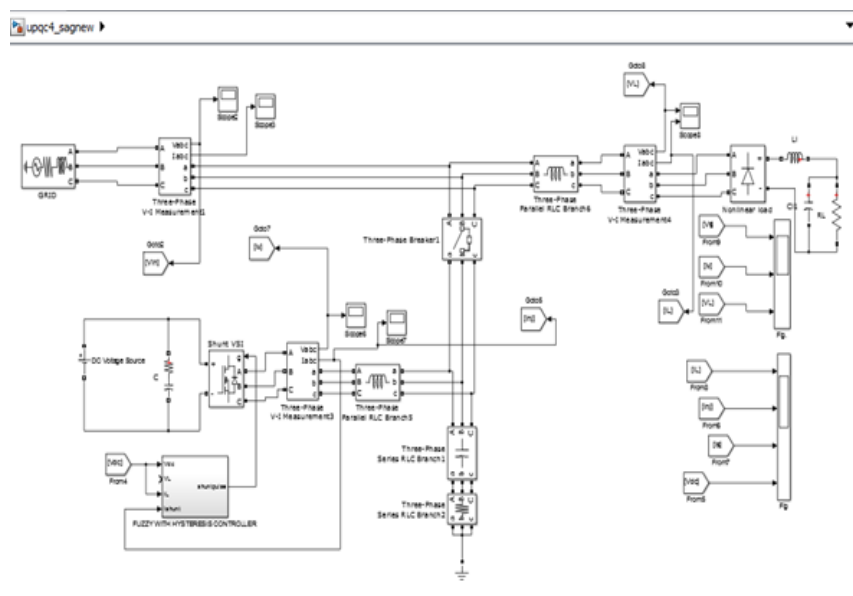

Fig. 7.Simulink model of hybrid converter

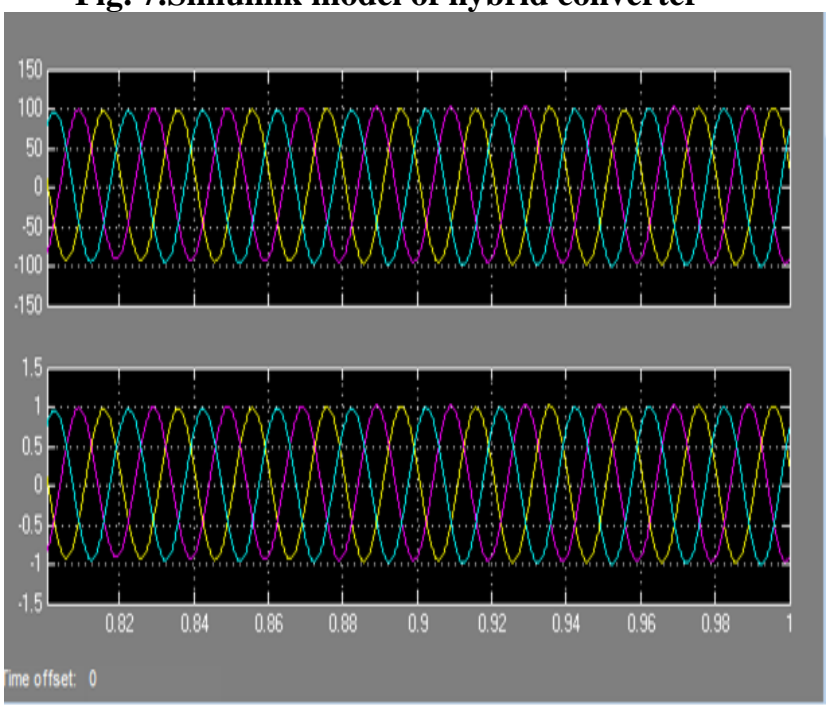

Fig. 8.Generated wind input power

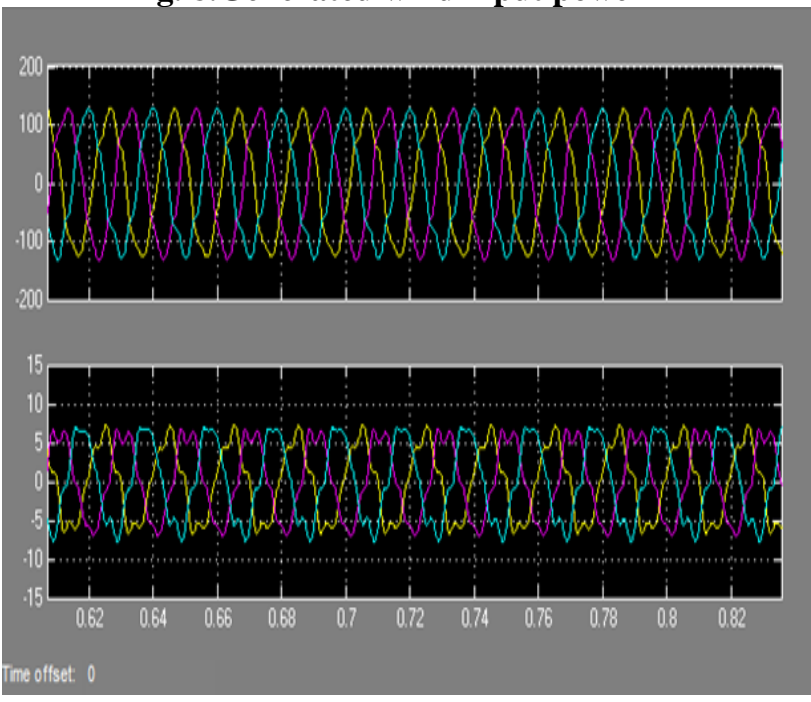

Fig. 9.The non-phase current waveforms

The power flow to the distribution system is around $100 \mathrm{~V}$ from the tied grid as shown in figure. 8. The distribution system is providing the energy to loads. The distortions in current presented if the faults or non linear loads are occurred. The distorted current is illustrated in figure. 9. By controlling the system using fuzzy with Hysteresis controller the current is comeback to in phase with respect to three phase voltage. The current in phase of power quality is shown in figure. 10.

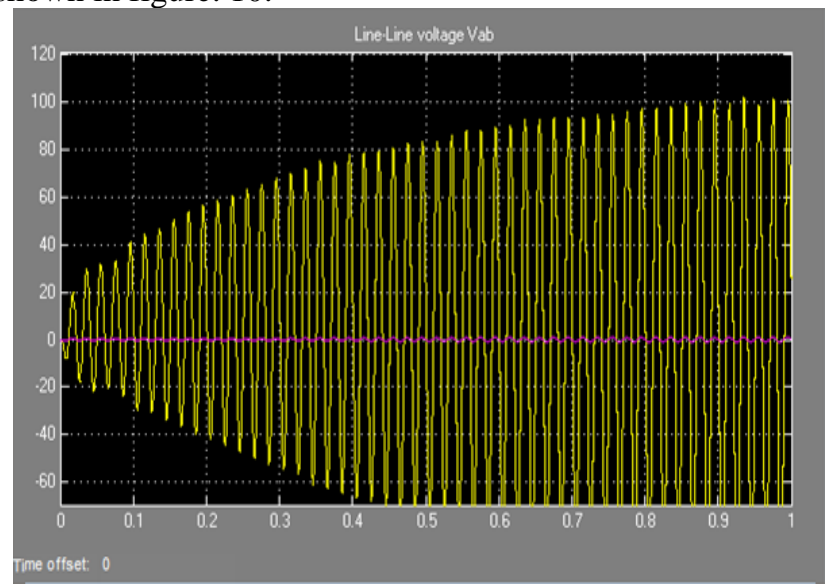

Fig. 10. The current in phase with respect to voltage

\section{CONCLUSION}

The power quality improvement of the grid connected distribution system is achieved using the voltage source inverter to compensate the voltage. The proposed quality improvement compensation method is controlled by using the fuzzy logic with $\mathrm{HC}$ controller. The reduced voltage or sag voltage is compensated with the help of inverter. The distorted current is controlled and compensated. This system results in the current which is distorted in phase with respect to voltage of the system. The aim of the proposed system is established using the fuzzy logic with hysteresis current controller. The results are obtained and verified using in MATLAB/Simulink.

\section{REFERENCES}

1. Viswanathan L, KUMAR S, “A review: Control strategies for power quality improvement in microgrid”. International Journal of Renewable Energy Research. vol. 11, 2018, pp. 150-65.

2. Prabhakar P, Vennila H," Power quality improvement in micro grid using custom power devices". International Journal of Enterprise Network Management. vol. 8, 2017, pp.327-339.

3. Mamatha B, Reddy CR, Nagaraju GV. "Power quality improvement in distribution grids with STATCOM based voltage regulator". International Journal of Research. vol. 7, 2018, pp. 42-48.

4. Kececioglu OF, Acikgoz H, Yildiz C, Gani A, Sekkeli M, "Power quality improvement using hybrid passive filter configuration for wind energy systems". Journal of Electrical Engineering \& Technology. vol. 12, 2017, pp.207-216.

5. Dharavath R, Raglend IJ, Manmohan A. "Implementation of solar PV-battery storage with DVR for power quality improvement". Innovations in Power and Advanced Computing Technologies. 2017, pp. 1-5.

6. Hashempour MM, Lee TL, Savaghebi M, Guerrero JM. "Real-time supervisory control for power quality improvement of multi-area microgrids". IEEE Systems Journal. vol.13, 2018, pp. 864-874.

7. Shiva C, Bhavani R, Prabha NR." Power quality improvement in a grid integrated solar PV system". IEEE International Conference on Intelligent Techniques in Control, Optimization and Signal Processing, 2017, pp. 1-6.

8. Dash SK, Ray PK. "Photovoltaic tied unified power quality conditioner topology based on a novel notch filter utilized control algorithm for power quality improvement". Transactions of the Institute of Measurement and Control. vol. 41, 2019, pp. 1912-1922.

Published By:

Blue Eyes Intelligence Engineering 
9. Bawa A, Uthman M, Shaibu FE, Oyewale KS. "Optimal Sizing and Sitting of Distributed Generation for Power Quality Improvement of Distribution Network". European Journal of Engineering Research and Science. vol. 15, 2019, pp. 18-23.

10. Shetty S, Suresh HL, Sharanappa M, Ramesh CV. "Performance of Wind Energy Conversion System During Fault Condition and Power Quality Improvement”. Emerging Research in Computing, Information, Communication and Applications, 2018, pp.211-225.

11. Paramanik S, Sarker K, Chatterjee D, Goswami SK. "Smart Grid Power Quality Improvement Using Modified UPQC". Devices for Integrated Circuit, vol. 23, 2019, pp. 356-360.

12. Tahir U, Ali SA, Azeem O, Khan O, Muzzammel R. "THD improvement of phase voltages via injection of voltage in neutral conductor for three phase four wire distribution system". International Conference on Computing, Mathematics and Engineering Technologies, vol. 3, 2018, pp. 1-5.

13. Kumar H. B. "Power quality improvement for wind energy conversion system using composite observer controller with fuzzy logic". International Journal of Intelligence Systems and Applications. vol. 10, 2018, pp. 72-80

\section{AUTHORS PROFILE}

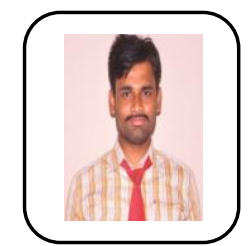

K. venkateswarlu obtained his B.Tech degree in Electrical \& Electronics Engineering from J.N.T. University, Kakinada in 2008. He obtained his M.Tech degree in Power Systems from J.N.T. University, Kakinada India. He is presently working as Assistant Professor in the department of Electrical and Electronics Engineering in PACE Institute of Technology \& Sciences, Ongole, Andhra Pradesh, India. His areas of interest are Power Systems and Electrical machines.

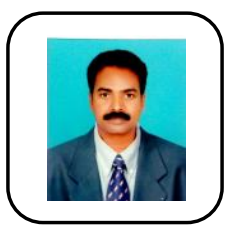

G.V.K Murthy obtained his B.E degree in Electrical \& Electronics Engineering from UCE, Andhra University, Visakhapatnam, India in 1999. He obtained his M.Tech degree in Electrical Power Engineering from UCE, J.N.T.University, Hyderabad, India and did his Ph.D from J.N.T. University, Kakinada, India. He is presently working as Professor \& Head in the department of Electrical and Electronics Engineering in PACE Institute of Technology \& Sciences, Ongole, Andhra Pradesh, India. His areas of interest are Power Systems, Electrical Distribution Systems and Electrical machines.

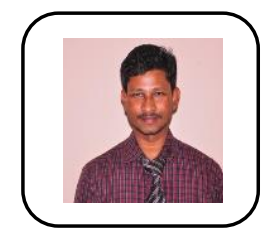

D.Prasad obtained his B.Tech degree in Electrical \& Electronics Engineering from J.N.T. University in 2005. He obtained his M.Tech degree in Power Electronics from NIT, Calicut India. He is presently working as Assistant Professor in the department of Electrical and Electronics Engineering in PACE Institute of Technology \& Sciences, Ongole, Andhra Pradesh, India. His areas of interest are Power Electronics and Control Systems.

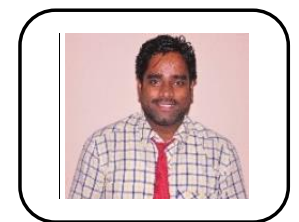

K.V Narayana obtained his B.Tech degree in Electrical \& Electronics Engineering from J.N.T. University in 2007. He obtained his M.Tech degree in Power Systems from J.N.T. University, Kakinada India. He is presently working as Assistant Professor in the department of Electrical and Electronics Engineering in PACE Institute of Technology \& Sciences, Ongole, Andhra Pradesh, India. His areas of interest are Power Systems and Electrical machines. 